[Agr. Biol. Chem., Vol. 31, No. 5, p. 628 632, 1967]

\title{
Observation on Plasma Free Amino Acids of Cow under Different Feeding
}

\author{
By Koichi Shimbayashi, Yu Ide and Toshio Yonemura \\ National Institute of Animal Health, Kodaira-city, Tokyo \\ Received January 16, 1967
}

\begin{abstract}
The influence of nutritional alteration to the plasma amino acid patterns in cows was investigated. The ratio of the essential to nonessential amino acids $(E / N)$ at 6 months after change of diet was higher in the group fed a high protein and low energy diet than the group fed a moderate protein and moderate energy diet (the control group). The total nonessential amino acid levels decreased in the former group. The decrease was due to lower values for glycine, alanine and glutamic acid.

On the other hand, the $\mathrm{E} / \mathrm{N}$ radio was lower in groups fed low protein diets than in the control group and total essential amino acid levels were lower in the former group than in the control group. The decrease was due to lower values for valine, threonine and arginine. Conversely, the higher values in glycine, serine and proline than those in the control group were observed.
\end{abstract}

Considerable information has been accumulated concerning the nutritional problem of protein. Recently, Zimmerman and Scott ${ }^{11}$ have indicated the relationship between amino acids requirement and their concentrations in the plasma of chick. Swendseid et al. ${ }^{2}$ have shown that the plasma essential amino acid values, especially that of valine, in the plasma of men decreased throughout the feeding on low protein diets.

It is well known that protein metabolism is influenced by energy intake, although the underlying biochemical mechanism remains obscure. ${ }^{31}$ In the present paper, emphasis is

1) R. A. Zimmerman and H. M. Scott, J. Nutrition, 87, 13 (1965).

2) M. E. Swendseid, S. G. Tuttle, W. S. Figueroa, D. Mulcare, A.J. Clark and F.J. Massey, ibid., 88, 239 (1966)

3) H.N. Munro and D.J. Naismith, Biochim. J., 54, 191 (1953). placed on changes in the concentration of free amino acids of milking cow under unbalanced diets in relation to protein and energy levels.

\section{EXPERIMENT}

Animals. The animals used in the experiment were adult female Holstein cows. They were 3 to 6 years of age and at two to four lactation stages. Their body weight and milk yield are shown in Table II. They were kept at this institute during the experimental period, being fed twice a day, in the morning and in the evening, and allowed to drink water ad libitum.

Experimental group and dietary regime. For the initial two months of the experimental period, all the animals were fed a diet consisting of pasturegrass hay, formula feed I, beet pulp, and wheat bran. This diet contained 110 to $120 \%$ of the digestible crude protein (DCP) and total digestible nutrients (TDN), both of which had been prescribed in the nutrient requirements established by the National 
Research Council of the National Academy of Science, United States of America (NRC). 4) After that period, the animals were divided into five groups of 4 head each. Each group was fed the diet given below.

Group 1. This group served as control. Each animal of this group was fed 5 to $8 \mathrm{~kg}$ of pasturegrass hay, 4 to $6 \mathrm{~kg}$ of formula feed I, 0.6 to $2.5 \mathrm{~kg}$ of beet pulp, and $0.5 \mathrm{~kg}$ of wheat bran everyday.

Group 2. During the control period, the animals of this group were fed a ration consisting of $7 \mathrm{~kg}$ of pasture-grass hay and $3 \mathrm{~kg}$ of formula feed $\mathrm{I}$. They were then fed a ration composed of $5 \mathrm{~kg}$ of formula feed II and $3 \mathrm{~kg}$ of pasture-grass hay. The DCP and TDN given to the animals of this group were 220 to $240 \%$ and 65 to $70 \%$ of the NRC nutrient requirements, respectively.

Group 3. The animals of this group were fed 7 to $8 \mathrm{~kg}$ of pasture-grass hay, $5 \mathrm{~kg}$ of formula feed I, and $3 \mathrm{~kg}$ of beet pulp at first, and then $3.2 \mathrm{~kg}$ of formula feed III, $4 \mathrm{~kg}$ of rice straw, and $5 \mathrm{~kg}$ of starch pulp daily. The DCP and TDN contained in these rations were 55 to $65 \%$ and 110 to $120 \%$ of the NRC nutrient requirements, respectively.

Group 4. The animals of this group were fed a ration containing 7 to $8 \mathrm{~kg}$ of pasture-grass hay, 4 to $6 \mathrm{~kg}$ of formula feed $\mathrm{I}$, and $3 \mathrm{~kg}$ of beet pulp during the control period. Then they were fed an experimental diet consisting of 3.6 to $4.0 \mathrm{~kg}$ of pasture-grass hay, 2.5 to $4.0 \mathrm{~kg}$ of formula feed $\mathrm{I}$, and 1.4 to 1.5 $\mathrm{kg}$ of beet pulp daily. Both DCP and TDN given were 85 to $95 \%$ of NRC nutrient requirements.
Group 5. The animals of this group were fed $7 \mathrm{~kg}$ of pasture-grass hay, 3 to $5 \mathrm{~kg}$ of formula feed $\mathrm{I}$, and $1 \mathrm{~kg}$ of beet pulp during the control period. Then they were fed $3 \mathrm{~kg}$ of formula feed IV, $2 \mathrm{~kg}$ of pasture-grass hay, and $1 \mathrm{~kg}$ of rice straw daily. The DCP and TDN of the experimental diet were 60 to $70 \%$ and 70 to $75 \%$ of the NRC nutrient requirements, respectively.

Feedstuffs. The feedstuffs employed in the present studies were composed of four kinds of formula feeds, pasture-grass hay, beet pulp, starch pulp, wheat bran, and rice straw. The actual compositions of the formula feeds, as indicated in percentage, were as follows. Formula feed I: soybean meal, 10.0; barley, 25.0 ; linseed meal, 10.0; corn, 16.0; wheat bran, 25.0; rice bran, 10.0 ; calcium carbonate, 2.5 ; sodium chloride, 1.0 ; trace elements, 0.05 ; inorganic phosphorus, 0.35; and vitamin $\mathrm{A}$ and $\mathrm{D}$ supplement, 0.1 . Formula feed II: soybean meal, 50.21; linseed meal, 33.47 ; corn, 3.35 ; starch pulp, 11.16; calcium carbonate, 0.58 ; sodium chloride, 1.12 ; trace elements, 0.04 ; and vitamin $\mathrm{A}$ and $\mathrm{D}$ supplement, 0.07. Formula feed III: corn, 15.7; wheat bran, 15.7; rice bran, 63.5; sodium chloride, 1.2 ; trace elements, 0.05 ; inorganic phosphorus, 3.8, and vitamin $A$ and $D$ supplement, 0.05. Formula feed IV: linseed meal, 5.52, corn, 80.57; starch pulp, 11.04; sodium chloride, 1.10; trace elements, 0.04 ; bone meal, 1.66 ; and vitamin $A$ and D supplement, 0.07. Takeda minefeed M was used for trace elements and Takeda 303 was used for vitamin A and D supplement. The chemic al

Table I. Chemical Composition of the Feedstuffs

$\begin{array}{lcccccc} & \text { Moisture } & \begin{array}{c}\text { Crude } \\ \text { protein }\end{array} & \text { Crude fat } & \text { Ash } & \begin{array}{c}\text { Crude } \\ \text { fiber }\end{array} & \begin{array}{c}\text { N-free } \\ \text { extract }\end{array} \\ \text { Formula feed I } & \% \% & \% & \% & \% & \% & \% \\ \text { Formula feed II } & 11.00 & 18.64 & 3.95 & 5.10 & 4.47 & 56.84 \\ \text { Formula feed III } & 8.04 & 36.82 & 2.45 & 6.48 & 4.00 & 42.21 \\ \text { Formula feed IV } & 14.00 & 14.81 & 3.40 & 7.27 & 5.39 & 55.13 \\ \text { Pasture-grass hay } & 8.41 & 11.01 & 3.79 & 3.26 & 8.52 & 65.01 \\ \text { Beet pulp } & 15.13 & 8.39 & 2.28 & 6.36 & 26.67 & 40.17 \\ \text { Starch pulp } & 15.97 & 6.56 & 0.23 & 2.72 & 16.25 & 58.27 \\ \text { Wheat bran } & 13.67 & 4.37 & 1.61 & 8.86 & 4.75 & 56.74 \\ \text { Rice straw } & 14.43 & 15.50 & 4.87 & 3.31 & 6.28 & 55.61 \\ & 13.50 & 4.10 & 1.30 & 15.30 & 28.90 & 36.90\end{array}$

4) Committee on Animal Nutrition, National Research Council: Nutrient Requirements of Diary Cattle. Publ. No. 464, $1 \sim 30$, National Academy of Science-National Research Council, Washington, D.C. (1958). 
Table II. Changes in Body Weight and Milk Yield

\begin{tabular}{|c|c|c|c|c|c|c|}
\hline \multirow{2}{*}{$\begin{array}{c}\text { Group } \\
\text { No. }\end{array}$} & \multicolumn{2}{|c|}{ Feeding schedule } & \multirow{2}{*}{$\begin{array}{l}\text { Control } \\
\text { period }\end{array}$} & \multicolumn{3}{|c|}{ Time after change of diet (months) } \\
\hline & DCP & TDN & & $1 \sim 2$ & $3 \sim 4$ & $5 \sim 6$ \\
\hline \multirow[t]{2}{*}{1} & $110 \sim 125$ & $100 \sim 120$ & $494 \pm 67 \mathrm{~kg}$ & $512 \pm 86$ & $520 \pm 93$ & $529 \pm 99$ \\
\hline & & & $11.5 \pm 0.4 \mathrm{~kg} / \mathrm{day}$ & $11.0 \pm 0.7$ & $10.6 \pm 0.4$ & $10.8 \pm 0.4$ \\
\hline \multirow[t]{2}{*}{2} & $220 \sim 240$ & $65 \sim 70$ & $411 \pm 11$ & $373 \pm 13$ & $357 \pm 14$ & $348 \pm 17$ \\
\hline & & & $7.4 \pm 1.5$ & $5.2 \pm 1.5$ & $3.7 \pm 1.6$ & $1.6 \pm 1.2$ \\
\hline \multirow[t]{2}{*}{3} & $55 \sim 65$ & $110 \sim 120$ & $475 \pm 31$ & $471 \pm 37$ & $463 \pm 27$ & $460 \pm 24$ \\
\hline & & & $11.5 \pm 1.4$ & $6.8 \pm 1.1$ & $5.7 \pm 1.4$ & $5.4 \pm 1.2$ \\
\hline \multirow[t]{2}{*}{4} & $85 \sim 95$ & $85 \sim 95$ & $501 \pm 15$ & $464 \pm 13$ & $441 \pm 17$ & $438 \pm 27$ \\
\hline & & & $12.1 \pm 5.0$ & $7.1 \pm 1.8$ & $6.0 \pm 1.7$ & $6.1 \pm 1.3$ \\
\hline \multirow[t]{2}{*}{5} & $60 \sim 70$ & $70 \sim 75$ & $470 \pm 29$ & $398 \pm 32$ & $378 \pm 31$ & $369 \pm 33$ \\
\hline & & & $10.0 \pm 2.2$ & $6.5 \pm 1.7$ & $5.9 \pm 0.9$ & $4.9 \pm 3.4$ \\
\hline
\end{tabular}

Average \pm S.D. values are shown for each feeding period. The value for body weight and that for milk yield are shown at the upper and the lower line of each article, respectively. TDN and DCP values are expressed as percentages to the Nutrient Requirements by NRC.4)

compositions of these feeds are shown in Table I.

Analytical method. Blood for amino acid analysis was withdrawn from the jugular vein before feeding in the morning. The blood was processed according to the procedures described in previous paper5) and the amino acids were measured in picric acid extracts of plasma by ion-exchange chromatography. ${ }^{6}$ )

\section{RESULTS}

Change in body weight. The results are presented in Table II. All the animals of group 1 increased in body weight during the experimental period. The animals of groups 2,4 , and 5, all of which were fed rations with low TDN, showed a marked decrease in body weight. TDN intake seemed to be essential for the maintenance of body weight. The animals of groups 3 maintained almost the constant level of body weight, although they were fed rations with low DCP.

Changes in milky yield. During the experimental period, the animals of group 1 showed a gradual decrease in milk yield, although the rate of decreasing was low. The animals of group 2 exhibited a rapid decreased in milk yield. The animals of groups 3,4, and

5) K. Shimbayashi and T. Yonemura, Nat. Inst. Anim. Hlth Quart., 3, 36 (1963).

6) S. Moore, D. H. Spackman and W. H. Stein, Alalyt. Chem., 30, 1185 (1958).
5, all of which were fed rations with low DCP, manifested a decrease in milk yield. In these animals, the rate of decrease in milk yields was high for one month after the change of diet, and then it became relatively low.

Free amino acids in plasma. Free amino acids in the plasma were determined at the 6th month after change of diets. The results obtained are summarized in Table III. The concentrations of taurine, aspartic acid, threonine, serine, glutamic acid, glycine, alanine, isoleucine, tyrosine, phenylalanine, and histidine were lower in group 2 than in group 1 as control. This tendency was the most remarkable in the case of glycine and alanine. The concentrations of valine, leucine, and arginine in group 2 were very close to those in group 1. Conversely, the concentration of proline was high. Generally, most amino acids were lower in concentration in group 3 than in group 1. Total concentration of nonessential amino acids in group 3, however, was higher than that in group 4 . The most important finding was the significantly high level of glycine concentration in group 3. The concentration of most neutral and acidic amino acids in group 4 were lower than those in group 1, but the concentration of basic 
Table III. Free Amino Acids in the Plasma of Cows at Six Months OF EXPERIMENTAL FEEDING ${ }^{1 ;}$

Amino acid

Essential
Threonine
Valine
Methionine
Isoleucine
Leucine
Phenylalanine
Lysine+ornithine
Histidine
Arginine
Total
Nonessential

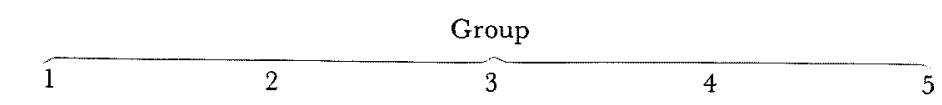

$\begin{array}{rr}1.25 \pm 0.37 & 1.06 \pm 0.17 \\ 2.51 \pm 0.16 & 2.50 \pm 0.36 \\ 0.39 \pm 0.01 & 0.22 \pm 0.11 \\ 1.40 \pm 0.40 & 1.27 \pm 0.11 \\ 1.49 \pm 0.07 & 1.54 \pm 0.26 \\ 1.10 \pm 0.10 & 0.66 \pm 0.00 \\ 2.81 \pm 0.86 & 2.51 \pm 0.81 \\ 1.30 \pm 0.27 & 0.92 \pm 0.27 \\ 1.53 \pm 1.02 & 1.56 \pm 0.42 \\ 13.79 \pm 1.33 & 12.24 \pm 2.15\end{array}$

$0.85 \pm 0.43$
$2.06 \pm 0.35$
$0.21 \pm 0.15$
$1.17 \pm 0.06$
$1.11 \pm 0.11^{*}$
$0.80 \pm 0.29$
$2.41 \pm 0.20$
$1.12 \pm 0.08$
$0.97 \pm 0.22$
$10.70 \pm 0.95$

$0.78 \pm 0.05$

$1.15 \pm 0.13$

$1.60 \pm 0.44^{*} \quad 1.66 \pm 0.09^{* *}$

$0.20 \pm 0.04 * * \quad 0.40 \pm 0.08$

$1.14 \pm 0.25 \quad 1.11 \pm 0.21$

$1.12 \pm 0.35 \quad 1.07 \pm 0.15 *$

$0.60 \pm 0.19 * \quad 1.06 \pm 0.10$

$3.02 \pm 0.42 \quad 2.14 \pm 0.15$

$1.30 \pm 0.09 \quad 1.42 \pm 0.19$

$1.54 \pm 0.23 \quad 1.33 \pm 0.05$

$11.30 \pm 3.86 \quad 11.34 \pm 0.73$

$\begin{array}{lcllll}\text { Serine } & 1.16 \pm 0.10 & 0.97 \pm 0.15 & 1.71 \pm 0.18^{*} & 1.13 \pm 0.51 & 1.50 \pm 0.20 \\ \text { Aspartic acid } & 0.57 \pm 0.09 & 0.49 \pm 0.18 & 0.17 \pm 0.04^{*} & 0.15 \pm 0.02^{*} & 0.35 \pm 0.04 \\ \text { Glutamic acid } & 1.16 \pm 0.28 & 0.87 \pm 0.11 & 1.61 \pm 0.19 & 1.90 \pm 0.30 & 1.10 \pm 0.34 \\ \text { Citrulline } & 1.86 \pm 0.17 & 1.56 \pm 0.59 & 0.38 \pm 0.03^{* *} & 0.45 \pm 0.27 * * & 1.67 \pm 0.37 \\ \text { Proline } & 0.69 \pm 0.17 & 1.21 \pm 0.31 & 1.41 \pm 0.32^{*} & 0.96 \pm 0.19 & 1.76 \pm 0.41^{*} \\ \text { Glycine } & 2.74 \pm 0.39 & 1.60 \pm 0.05^{*} & 3.63 \pm 0.47^{*} & 2.24 \pm 0.17 & 3.27 \pm 0.49 \\ \text { Alanine } & 2.54 \pm 0.12 & 1.53 \pm 0.05^{* *} & 2.05 \pm 0.25 & 2.32 \pm 0.88 & 2.41 \pm 0.41 \\ \text { Tyrosine } & 1.13 \pm 0.02 & 0.73 \pm 0.07^{* *} & 0.90 \pm 0.05^{* *} & 0.50 \pm 0.10^{* *} & 1.06 \pm 0.11 \\ \text { Taurine } & 0.64 \pm 0.16 & 0.50 \pm 0.10 & 0.56 \pm 0.15 & 0.50 \pm 0.14 & 0.53 \pm 0.05 \\ \quad \text { Total } & 12.49 \pm 1.30 & 9.46 \pm 0.78^{*} & 12.42 \pm 1.33 & 10.15 \pm 2.23 & 13.65 \pm 1.65 \\ \text { E/N ratio } & 1.08 \pm 0.22 & 1.29 \pm 0.15 & 0.86 \pm 0.03 & 1.10 \pm 0.12 & 0.83 \pm 0.07\end{array}$

1) These values are expressed in $\mathrm{mg} / 100 \mathrm{ml}$ of plasma and the \pm symbol indicates $\mathrm{SD}$ of mean.

2) E/N ratio showed significant differences in groups 2,3 , and 5 from the value is group 1 at $\mathrm{P}<0.2, \mathrm{P}<0.1$ and $\mathrm{P}<0.1$, respectively, by $t$ test.

*, ** Significant differences from values for group 1 as control at $1 \%$ and $0.1 \%$ levels, respectively.

amino acids in group 4 was similar to that in group 1. The concentrations of aspartic acid, citrulline, valine, isoleucine, leucine, lysine, and arginine were lower in group 5 than in group 1 . The concentrations of threonine, glutamic acid, alanine, methionine, tyrosine, and histidine in group 5 were close to those in group 1. Conversely, the concentrations of serine, proline, and glycine in group 5 were higher than those in group 1 .

As a consequence of these changes in the plasma amino acid levels, the ratio of the essential to the nonessential acidic and neutral amino acids $(\mathrm{E} / \mathrm{N})$ at 6 th month was lower in groups 3 and 5 , all of which were fed rations with low DCP, than in group 1 , which was fed ration with moderate DCP. The E/N ratio of group 4 was almost the same as that in group 1. The higher value of $\mathrm{E} / \mathrm{N}$ ratio was obtained in group 2, which was fed ration with high DCP.

\section{DISCUSSION}

The decrease of body weight in group 2, which was fed a ration with markedly high DCP, was observed (Table II). It is well known that ammonia is absorbed from the rumen into the portal blood stream and converted by the liver into urea." ${ }^{7}$ Since it is also known that the amount of ammonia

7) L.W. McDonald, Biochem. J., 42, 584 (1948). 
absorbed is influenced by dietary protein level, ${ }^{8.91}$ the dietary nitrogen in group 2 might be absorbed as ammonia from the rumen to the greatest extent. Most ammonia absorbed might have been excreted in the form of urea into urine, and consequently the rate of nitrogen loss might have been great. Likewise a larger amount of energy would be wasted for urea synthesis in the liver.

The concentration of serum urea nitrogen in group 2 was more than twice times as high as that in group 1 as control (the result is not tabulated). Such a high concentration of urea nitrogen might be due not only to ammonia absorbed from the rumen, but also to the tissue protein as an energy source. Total amount of the essential amino acids in group 2 was similar to that in group 1 . Total amount of the nonessential amino acids, however, was lower than that in group 1 . The high $E / N$ ratio might be indicative of increased gluconeogenesis.

The E/N ratio of group 4, which was fed a ration with low DCP, was almost same as that in group 1, but the former group showed a markedly low amount of total amino acids. This group showed a rapid decrease of body weight for up to 2 months, but no changes at the end of experiment. Accordingly, nitrogen loss might have taken place in the early stage and might have achieved to nitrogen equilibrium at the end of experiment.

Group 3 and 5, all of which were fed rations with low DCP, showed the lower $\mathrm{E} / \mathrm{N}$ ratio than group 1 as control. Group 3 was fed a ration with adequate energy, but this low DCP ration appeared to be slightly difficult for this group to tolerate. The concentrations of valine, arginine, and threonine

8) D. Lewis, K. J. Hill and E. F. Annison, Biochem. J., 66, 587 (1957).

9) K. Kameoka and H. Morimoto, Bull. Nat. Inst. Agr. Sci., Ser. G., No. 21, 188 (1962). were very low, whereas high values were observed for glycine, proline, and serine.

There is a report indicating that increment of the first-limitating amino acid (lysine, arginine, or valine) resulted in a progressive decline in plasma threonine. ${ }^{11}$ However, in spite of the decrease of plasma valine in the groups, which were fed rations with low DCP, the increase of threonine was not observed.

Generally, glycine is very abundant in the plasma of ruminant ${ }^{51}$ and alanine is higher level than glycine in men. ${ }^{10}$ The high concentration of glysine in groups 3 and 5 might be comparable with the high concentration of alanine in men, which were fed rations with adequate calorie and extremely low protein. ${ }^{21}$ Glycine is the most abundant of all the amino acids in the bone. Since changes caused by varying the energy content of a diet containing protein are remarkable in muscle, skin, bone, and adipose tissue, ${ }^{3 \prime}$ it is assumed that the high glycine level in the plasma may be partly related to the acceleration of the rate of metabolism of collagenous protein in groups 3 and 5.

The similar plasma amino acid pattern to that of rat and rabbit, all of which were under the condition of fasting, was not observed in groups 4 and $5 .{ }^{11,121}$ Therefore, the complete absence of energy appears to prevent the response of the nonessential amino acids as Swendseid et al. ${ }^{2 !}$

Since life in mammals will be sustained by the relatively small range of different protein and energy levels, changes caused by mild alterations of protein and energy intakes should be investigated in future.

10) W. H. Stein, J. Biol. Chem., 211, 915 (1954).

11 L. M. Henderson, P. E. Schurr and C. A. Elvehjem, ibid., 177, 815 (1949).

12) W. D. Block and R. W. Hubbard, Arch. Biochem. Biophys., 96, 557 (1962). 